\title{
Vivências de crianças e/ou adolescentes que esperam por adoção tardia
}

\author{
Experiences of children and / or adolescents waiting for late adoption
}

\author{
Érica Cavalheiro da Silva ${ }^{1 *}$, Giana Bernardi Brum Vendruscolo ${ }^{2} \theta$
}

\begin{abstract}
${ }^{1}$ Acadêmica do curso de Psicologia da Universidade Regional Integrada do Alto Uruguai e das Missões, Campus Santo Ângelo, Santo Ângelo, Rio Grande do Sul, Brasil. ${ }^{2}$ Professora orientadora do trabalho de conclusão de curso da Universidade Regional Integrada do Alto Uruguai e das Missões, Campus Santo Ângelo, Santo Ângelo, Rio Grande do Sul. *Autor para correspondência. E-mail: ericasilva@aluno.santoangelo.uri.br
\end{abstract}

\begin{abstract}
Resumo: Introdução: A adoção sempre foi considerada complexa no que se refere ao fato de que na maioria das vezes ela acontece para solucionar o problema de infertilidade do casal, e ainda não é a primeira escolha feita por eles, que antes recorrem a procedimentos clínicos na tentativa de concretizarem o sonho da maternidade/paternidade. Material e métodos: Esta pesquisa tem por objetivo analisar as vivências de crianças e/ou adolescentes que esperam pela adoção. Realizou-se uma pesquisa qualitativa, descritiva e exploratória com delineamento de estudo de caso. A amostra utilizada nessa pesquisa foi composta por duas crianças acima de sete anos que esperam a adoção, o instrumento utilizado foi uma entrevista semiestruturada contendo sete perguntas e os dados analisados através da análise de conteúdo. Resultados e discussões: A maioria das crianças e adolescentes aparenta ter consciência dos motivos que as fizeram serem retiradas de suas famílias biológicas, e colocadas em ambientes institucionais, no entanto, muitas vezes é no abrigo que elas recebem a atenção e o cuidado que não tiveram nas suas famílias de origem, podendo tornar a institucionalização uma experiência melhor. Considerações: Para as crianças e/ou adolescentes que se encontram no abrigo, a adoção é uma forma de construir ou em alguns casos reconstruir muitas coisas, entre elas sua história, seu interior que pode ter sido despedaçado por aqueles que tinham o dever de prezar pelo seu bem-estar, mas que assim não o fizeram, chance de saber realmente o que é uma família, de receberem um amor que não os machucará.
\end{abstract}

Palavras-chave: crianças, adolescentes, institucionalização, adoção.

\begin{abstract}
Introduction: Adoption has always been considered complex with regard to the fact that most of the time it happens to solve the couple's infertility problem, and it is still not the first choice made by them, who before resort to clinical procedures in an attempt to realize the dream of motherhood / paternity. Material and methods: This research aims to analyze the experiences of children and / or adolescents who are waiting for adoption. A qualitative, descriptive and exploratory research was carried out with a case study design. The sample used in this research was composed of two children over seven years old waiting for adoption, the instrument used was a semi-structured interview containing seven questions and the data analyzed through content analysis. Results and discussions: Most children and adolescents seem to be aware of the reasons that caused them to be removed from their biological families, and placed in institutional settings, however, it is often in the shelter that they receive the attention and care that they did not have. in their families of origin, making institutionalization a better experience. Considerations: For children and / or teenagers who are in the shelter, adoption is a way to build or in some cases reconstruct many things, including their history, their interior that may have been shattered by those who had a duty to cherish for their well-being, but who did not do so, chance to really know what a family is, to receive a love that will not hurt them.
\end{abstract}

Keywords: children, adolescents, institutionalization, adoption.

\section{Introdução}

Esta pesquisa teve início a partir de questões acerca de que muito se fala e se estuda sobre as crianças que são adotadas ainda bebês, quando a procura é bem maior, mas, e as crianças que passam dessa idade, como elas se sentem? O que elas pensam sobre isso? Será que elas ainda acreditam na adoção? Foi pensando nisso, que esta pesquisa teve como tema a adoção tardia.

Analisando de uma forma histórica, Vargas (1998) nos diz que a adoção já existia nos países de direito romanos, e se dava através da filiação conferida por um documento, como um certificado, que era dado aos 
pais adotantes, e dessa forma o nome biológico da criança que seria adotada era retirado, e ela continuaria levando adiante o nome da nova família. No entanto, tais adoções só eram permitidas pela lei se a pessoa que seria adotada tivesse idade acima de vinte e três anos, que era a idade da maioridade na época. As adoções de crianças menores eram feitas apenas por meio de contratos amigáveis entre os pais biológicos e os adotivos.

A adoção moderna, ao contrário da clássica, tem como objetivo proporcionar uma família para a criança que foi abandonada, e dessa forma solucionar o problema dessa criança (Pillotti, 1998 apud Vargas, 1998).

A adoção sempre foi considerada complexa no que se refere ao fato de que na maioria das vezes ela acontece para solucionar o problema de infertilidade do casal, e ainda não é a primeira escolha feita por eles, que antes recorrem a procedimentos clínicos na tentativa de concretizarem o sonho da maternidade/paternidade.

A adoção tardia é o nome dado para a adoção de crianças que já são maiores de dois anos de idade, podem ser vítimas de abandono por parte dos pais, podem ter sido retiradas pelo poder judiciário que julgou os pais incapazes de cuidá-las, ou que foram "deixadas de lado" nos orfanatos pelo Estado (Vargas, 1998).

Com base em dados estatísticos do Cadastro Nacional de Adoção (Conselho Nacional de Justiça [CNJ], 2018) pretendentes que aceitam adotar crianças com até dois anos de idade formam uma porcentagem de $15,37 \%$, enquanto que de pretendentes para crianças/adolescentes com idade até dezessete anos, constituise uma porcentagem de $0,12 \%$. E ainda há uma preferência maior por crianças/adolescentes de raça branca, com um total de $96 \%$ das escolhas.

No entanto há um contraste muito grande nos números quando se compara os interesses dos adotantes e o número de crianças que aguardam adoção. Como vimos o interesse por crianças de até dois anos é de 15\%, mas o número de crianças para essa faixa etária é de 4,83\%, enquanto que de crianças/adolescentes com dezessete anos é de 7,22\% (CNJ, 2018). Tais dados nos mostram que conforme as crianças vão ficando mais velhas, as chances de adoção também vão diminuindo significativamente, gerando mais incertezas sobre o seu futuro.

As crianças/adolescentes institucionalizadas percebem-se vivenciando questões produzidas por situações antagônicas. Mesmo sabendo que as instituições fornecem o básico para sua sobrevivência, acabam lhes afastando do convívio familiar, no caso daqueles que foram retirados de suas famílias (Zem-MascarenhaS \& Dupas, 2002).

A criação de vínculos afetivos é parte importante no desenvolvimento da criança desde o seu nascimento, no entanto, na questão de institucionalização, o que se investiga são quantas crianças conseguem experimentar esse desenvolvimento de forma mais adequada. Altoé (1988 apud Oliveira \& Próchno, 2009), "destaca as pobres condições afetivas que as crianças institucionalizadas vivem, e afirma que elas representam o modelo que resulta da carência de uma vinculação afetiva estável e permanente, e danos ocasionados por um ambiente opressivo, empobrecido e que limita o desenvolvimento infantil".

As questões afetivas e sentimentais são aspectos muito importantes para o desenvolvimento de um sujeito, por isso precisa-se dar mais atenção as crianças institucionalizadas que aguardam pela adoção, o que muitas das vezes não acontecem nos abrigos, já as crianças que aguardam a adoção e que estão inseridas no programa "Família acolhedora", usufruem mais desses cuidados.

Um estudo realizado por Carvalho e Manita (2010) apontou que a entrada nas instituições é uma experiência negativa para as crianças, marcada por tristeza, angustia e medo, no entanto, ao passar um tempo de adaptação, a experiência começa a se tornar mais positiva. As crianças também têm o desejo de regressar as suas casas, mas entendem que isso só é viável caso haja mudanças nas suas famílias, para que não a coloquem em riscos novamente.

A pergunta norteadora do trabalho é quais as vivências de crianças e/ou adolescentes acima de sete anos que esperam por adoção, e visa responder os seguintes objetivos: averiguar se a criança e/ou adolescente tem conhecimento do motivo que levou a destituição familiar; identificar o tempo que se encontra no abrigo; compreender o que elas pensam sobre o tema adoção; averiguar se já existiram tentativas de adoção durante o período na instituição e como foi este processo; demonstrar o sentimento das crianças e/ou adolescentes em relação a instituição em que está abrigada e verificar a expectativa dessas crianças para o futuro.

\section{Metodologia}

O tipo de pesquisa utilizado é a qualitativa, a classificação quanto aos objetivos é exploratória e descritiva e tem como delineamento o estudo de caso. A amostra utilizada nessa pesquisa foi composta por duas crianças acima de sete anos que esperam a adoção e que estão acolhidos no abrigo de um município da região Noroeste 
do estado do Rio Grande do Sul. O instrumento utilizado foi uma entrevista semiestruturada contendo sete perguntas e a forma de análise dos dados ocorreu através da análise do conteúdo.

\section{Resultados e discussão}

Segundo Oliveira e Próchno (2009), a adoção se caracteriza como uma prática eminentemente social e humanitária, constituindo a forma mais adequada para oferecer às crianças que necessitam de amparo e proteção um lugar para que possam se desenvolver e ter seus direitos garantidos. Como ponto de apoio, a instituição se transformou na alternativa mais apropriada para acolher crianças que, em conflito com a família de origem, não se encontram em condições de permanecer em casa, ou no convívio da mesma, em situações com caráter de violação dos direitos, e por consequência, a adoção acaba se tornando o melhor caminho para o futuro desta criança e/ou adolescente.

Caracterização dos sujeitos: O sujeito M., é um menino de 12 anos, e quando foi retirado de sua família, foi encaminhado para um abrigo onde ficou por um ano, depois, esse abrigo fechou e agora irá completar dois anos que está no abrigo municipal. O sujeito está abrigado junto com o seu irmão gêmeo, pois a mãe acabou falecendo devido a um câncer e a sua avó só tinha condições de ficar com as duas outras irmãs mais novas que o sujeito tem. Então a psicóloga do abrigo conversou com eles a respeito de adoção e questionou se eles tinham o interesse em ser adotados, e os dois concordaram, mas não querem ser separados, então aguardam uma família que queira adotar os dois.

O sujeito V. é uma menina de 11 anos e se encontra no abrigo desde setembro de 2018, a mãe era usuária de drogas, então ela e a sua irmã mais nova foram destituídas do poder familiar e levadas para o abrigo.

Neste tempo houveram tentativas de adoção por parte de alguns tios, mas que não foram bem-sucedidas em função de que a irmã, não faria parte do processo de adoção. O sujeito V. diz que sem a irmã não deseja ser adotada, e que se for necessário, quando ela fizer dezoito anos e sair do abrigo, irá adotar a irmã.

\section{Categoria 1- Motivo da destituição familiar}

Essa categoria visa investigar se os participantes da pesquisa têm conhecimento dos motivos pelo qual foram destituídos de suas famílias, fato que pode ser observado nas seguintes falas: [...] a última vez que eu sai da minha família, foi por causa que eu briguei na escola, daí o conselho me buscou[...] eu ia voltar pra minha família, mas não deu por causa que a minha mãe tava com câncer, ela não pode ficar com nós, por enquanto, daí ela morreu[...] ditas pelo sujeito M. e também [...]Eu sei que a minha mãe usava droga, só que quando as minhas colega me perguntam porque que eu vim pra cá eu não digo, eu digo que eu não sei porque eu não gosto de falar porquê[...] ditas pelo sujeito $\mathrm{V}$.

O poder familiar ocorre como uma obrigação legalmente conferida aos pais de gerenciar os bens e garantir o desenvolvimento dos direitos biológicos e psíquicos dos seus filhos. Todavia, esse poder pode ser interrompido ou destituído em casos e situações muito graves (Martins, 2014).

Segundo o artigo 1.635 do Código Civil (Lei n. 10.406/2002), o poder familiar pode ser destituído nos seguintes casos: a morte dos pais ou dos filhos, por emancipação ou maioridade, pois já será considerado adulto e capaz de exercer sozinho todas as condutas civis; em caso de adoção, o poder familiar passa da família de origem, automaticamente para a família adotante, ou por uma decisão do próprio juiz, e nesse caso, há outra lista de situações que levam a destituição familiar judicial (Brasil, 2002).

Com base em uma pesquisa realizada por Carvalho e Manita (2010), constatou-se que a maioria das crianças e adolescentes aparenta ter consciência dos motivos que as fizeram serem retiradas de suas famílias biológicas, e colocadas em ambientes institucionais, o que corrobora com este estudo, onde pode-se verificar que os sujeitos tinham total conhecimento dos motivos pelos quais estavam na instituição, mesmo que as vezes não gostem de expor estes motivos.

Para o sujeito M. não houve nenhum desconforto ao relatar os motivos pelo qual foi destituído da sua família, no entanto, para o sujeito V. foi um pouco mais difícil falar, pois ela sente vergonha de dizer que a mãe usava drogas, principalmente se alguém da escola lhe pergunta o motivo, em razão de que tem medo que toda a escola fique sabendo sobre isso, e não deseja que os outros saibam de sua realidade.

Segundo Trindade e Bunn (2017) as experiências que a criança tem em sua relação com a mãe, tanto positivas quanto negativas, inscreverão em sua subjetividade formas e tendências de lidar com a sociedade e perceber o mundo a sua volta. Dessa forma pode-se pensar que como o sujeito só foi retirada da mãe a pouco 
tempo, passou por questões negativas em relação a mãe, por esta ser usuária de drogas, o que também pode justificar a vergonha que ela tem em relação a situação da mãe.

A dependência química pode trazer consequências diversas à vida do usuário, da mesma maneira que das pessoas que constituem sua rede de relacionamentos, pois o uso de drogas, não raro, se torna prioridade na vida do dependente e, para dedicar-se ao uso, outros papéis e funções são descartados (Trindade \& Bunn, 2017). Como não sabemos todo o processo de retirada dessa criança da guarda da mãe, pensa-se que ela não deu a devida prioridade as filhas, em função da dependência química.

\section{Categoria 2 - Adoção e tentativas de adoção}

A categoria tem por objetivo analisar o que os sujeitos pensam sobre adoção e se durante o tempo na instituição houveram tentativas de adoção.

Para o sujeito M. adoção é: "Eu te uma família que me cuide bem, e que ela seja uma boa família pra mim conviver e ter uma família nova. " E para o sujeito V. [...]que é uma coisa legal porque quando as pessoas não podem voltar pras suas famílias, que não tem com quem morar é bom se tipo adotado, ir pra uma família nova com pessoas novas. [...]

E quanto as tentativas de adoção, M. disse [...] por enquanto não porque a gente não sabia disso dai a psicóloga falo com a gente [...] é bom por causa que nos podemo te uma família nova e conviver, e se feliz com ela. Já o sujeito V. disse [...] um tio e uma tia minha tentaram pegar minha guarda só que eles só queriam a minha guarda, não queriam da minha irmã. [...].

A adoção de crianças e adolescentes vem ganhando espaço nos meios de comunicação e na legislação brasileira, porém, o tema ainda é visto com um pouco de contradição, sendo envolvido por mitos e preconceitos, reação cultural da prevalência dos "laços de sangue" (Silva, 2009).

Segundo Vargas (1998), o termo "adoção tardia” é usado para designar as crianças acima de dois anos de idade que aguardam adoção, e muitos autores consideram maiores as crianças que já conseguem se ver diferenciadas do outro e do mundo, que não é mais um bebê, que de certa forma apresenta uma autonomia para atender suas necessidades básicas.

Os interesses das crianças e adolescentes que esperam a adoção devem ser priorizados, mais do que o desejo das pessoas que esperam na fila para fazer a adoção, no entanto percebe-se que isso não ocorre como deveria, pois, os requerentes tem a possibilidade de "escolher" a criança que mais lhe agrada e como queiram, deixando de lado os interesses das crianças (Silva, 2009).

As produções cientificas que abordam o tema adoção têm tentando cada vez mais envolver e se preocupar com a criança que passa por esse processo, no entanto, os estudos referentes a este tema, falam "sobre" a criança e não diretamente "com ela". Faz-se necessário conhecer os significados elaborados pela criança que está tendo esta vivência, pois é ela que constitui o processo de adoção (Gama \& Oliveira, 2018).

Foi possível averiguar que para os sujeitos da pesquisa, a adoção é algo bom, positivo, que poderá lhe dar novamente uma família, onde possam ter amor, que lhes proporcione cuidado e atenção, algo que sua família de origem não conseguiu lhes dar.

\section{Categoria 3 - Sentimentos em relação à instituição}

A categoria pretende averiguar os sentimentos que os sujeitos da pesquisa têm em relação a instituição em que estão inseridos. Para o sujeito M. a instituição [...] é boa e ela serve pra acolhe as pessoas[...] e para o sujeito V. [...] me sinto bem, porque aqui é um lugar pra gente morar um tempo, [...] é só até ou a gente volta pras nossas famílias ou a gente ir pra uma família nova, um lugar temporário[...].

A instituição de abrigo constitui um local de extrema importância para as crianças e/ou adolescentes institucionalizados, proporcionando que eles realizem atividades, funções e interações, desenvolvendo também relações recíprocas, equilibrando poder e afeto. Dessa forma, entende-se que a instituição pode sim ou não ter efeitos benéficos para a vida dessas crianças, e isso vai depender da condição em que ela consegue fornecer apoio e proteção a estas (Freitas, 2010).

Freitas (2010) entende que o ambiente institucional não é o mais adequado para o desenvolvimento de crianças e/ou adolescentes, pois acaba havendo um padrão no atendimento, há, muitas vezes um número elevado de crianças por cuidadores, uma falta de planejamento de atividades e também a fragilidade nas redes de apoio social e afetivo. Esses seriam alguns dos aspectos referentes aos prejuízos da institucionalização na vida do indivíduo. No entanto, ela pode ser a melhor saída, em casos e situações mais diversas nas famílias. 
A entrada nas instituições é uma experiência um pouco difícil, dolorosa, marcada por sentimento de tristeza, medo, solidão, nervosismo e vergonha, acontecimentos gerados pelo afastamento da família, amigos e escola. Logo quando dão a entrada nas instituições as crianças têm muito medo de não retornarem para casa, de não verem mais os irmãos e nem os pais, medo de não gostarem das pessoas do local e de não serem aceitas por elas também (Carvalho \& Manita, 2010).

No entanto, com o passar do tempo a criança começa a se adaptar a rotina do local que é regido por regras, e cria uma consciência de que as regras são boas para que as coisas sejam bem organizadas e facilitem a convivência, tornando-se fundamentais para o dia-a-dia, gerando nas crianças e/ou adolescentes expectativas para o futuro, tais como: terminar os estudos, conseguir um emprego e estabilizar suas vidas (Carvalho \& Manita, 2010).

Ainda assim é muito frequente afirmações de que a institucionalização não é tão boa para as crianças, e que ficar nesses locais por muito tempo esperando por adoção acaba trazendo consequências negativas para o futuro destes. Conforme os anos vão passando, as chances da adoção vão diminuindo para crianças acima de dois anos, e dessa forma, muitas destas crianças e adolescentes irão ficar nos abrigos até completarem dezoito anos, e não poderão desfrutar de uma família, que deveria ser lhe concedido por direito.

Podemos perceber dois pontos de vistas no que se refere as instituições de abrigo, onde no primeiro momento o autor cita que para a criança e/ou adolescente, a institucionalização só traz efeitos, sentimentos e vivências negativas. No entanto, ao observarmos as falas dos sujeitos da pesquisa, pode-se perceber que para eles, a instituição é um ótimo local, onde eles poderão ficar até que consigam uma família, onde são bem tratados e tem um bom relacionamento com os demais. Um dos fatores que podem contribuir para esse tipo de relação é que o abrigo em que eles se encontram, se localiza em uma cidade relativamente pequena, se comparada com grandes metrópoles, e por isso, as pessoas que trabalham no abrigo, conseguem proporcionar uma atenção melhor e de mais qualidade para as crianças e/ou adolescentes.

\section{Categoria 4 - Expectativas para o futuro}

O propósito desta categoria é conhecer quais são os planos e expectativas que os sujeitos da pesquisa planejam para o futuro. O sujeito M. disse [...] eu quero ser bombeiro, primeiro eu quero se forma na faculdade, depois se bombeiro, e te minha própria casa, meu próprio carro, minha própria família. [...]. Já o sujeito V. disse [...] eu quero ter a minha casa, quero ter a minha família, eu quero trabalhar [...].

A construção de expectativas quanto ao futuro tem ocorrido como uma importante parte da proteção do desenvolvimento saudável de adolescentes, pois os pensamentos sobre o futuro motivam os comportamentos cotidianos e intervém nas escolhas, decisões e atividades que prejudicarão a realização no seu futuro. A expectativa pode ser considerada também como a antecipação de metas pensadas para o futuro, no presente, e podem ser metas um tanto próximas e realistas, ou podem ser metas distantes e imprecisas (Zappe et al., 2013).

No caso dos sujeitos da pesquisa, ambos têm o desejo de constituírem suas próprias famílias no futuro, e também desejam trabalhar, sempre buscando maiores conhecimentos como podemos observar nesta fala do sujeito V. [...] por causa das diferentes línguas e diferentes culturas que a gente pode aprender[...], onde ela relatava o porquê de estar pensando em ser diplomata e ter descoberto o que tal profissão realiza. Isto demonstra o que Zappe et al. (2013) diz em relação as principais ideias que os adolescentes têm sobre o futuro, que são preocupações relacionadas à educação, trabalho, casamento e família.

Um ponto curioso nestes discursos, é que os sujeitos poderiam ter muito medo ou algum tipo de receio no que diz respeito a eles construírem suas famílias no futuro, devido à falta de amparo, responsabilidade, atenção e dever que tiveram das suas famílias de origem, no entanto, isto não é observado em nenhuma fala, pois ambos trazem o desejo de poder fazer esta construção.

\section{Considerações finais}

Com base nessa pesquisa foi possível perceber que as crianças e/ou adolescente institucionalizados que aguardam adoção passam por vários momentos e situações. Podem receber muito amparo das instituições, atenção e podemos dizer que até afeto, pois os funcionários do abrigo acabam desenvolvendo laços com os abrigados, mas tudo isso irá depender de como esta instituição lida e dá o suporte necessário para que essa relação seja boa e de qualidade.

Para as crianças e/ou adolescentes que se encontram no abrigo, a adoção é uma forma de construir ou em alguns casos reconstruir muitas coisas, entre elas sua história, seu interior que pode ter sido despedaçado por 
aqueles que tinham o dever de prezar pelo seu bem-estar, mas que assim não o fizeram, chance de saber realmente o que é uma família, de receberem um amor que não os machucará.

Mas mesmo que a cada ano que se passa, isto possa parecer mais distante, as crianças e/ou adolescentes desta pesquisa, têm a chance de estarem inseridas em uma instituição que preza muito o cuidado, o bemestar, e que procura da melhor forma, fazer com que elas se sintam acolhidas e sintam-se em uma família.

Outro ponto que merece destaque, é que existem poucos referenciais e estudos sobre a adoção na percepção das crianças, sobre a perspectiva dela, e não apenas sobre ela. A produção de estudos que visem esse conhecimento são de extrema importância para que possamos tornar a institucionalização e a espera pela adoção menos difícil para as crianças e/ou adolescentes que estão nesta condição.

\section{Referências}

Brasil. 2002. Lei 10406, de 10 de janeiro de 2002: Dispõe sobre o Código Civil. Disponível em: http://www.planalto.gov.br/ccivil_03/leis/2002/110406.htm. Acesso em: 02 jun. 2019.

Carvalho, T., \& Manita, C. 2010. Percepções de crianças e adolescentes institucionalizados sobre o processo de institucionalização e a experiência na instituição. Faculdade de Psicologia e de Ciências da Educação, Universidade do Porto. In Actas do VII Simpósio Nacional de Investigação em Psicologia. Universidade do Minho. Disponível em: repositorioaberto.up.pt/bitstream/10216/64468/2/87378.pdf. Acesso em: 01 jun. 2019.

Conselho Nacional de Justiça [CNJ]. 2018. Cadastro Nacional de Adoção. Disponível em: http://www.cnj.jus.br/programas-e-acoes/cadastro-nacional-de-adocao-cna. Acesso em: 02 jun. 2019.

Freitas, L. N. 2010. Modo de vida de crianças institucionalizadas. Porto Alegre, RS: Universidade Federal Do Rio Grande Do Sul. Porto Alegre, 2010. Disponível em: https://www.lume.ufrgs.br/handle/10183/28227 Acesso em: 05 jun. 2019.

Gama, J. F. A., \& Oliveira, M. C. M. F. 2018. Do desejo de ser adotado à adoção da família em meu desejo: discutindo saúde mental e adotabilidade. Universidade Católica de Pernambuco (UNICAP). Disponível em: http://www.conbracis.com.br/trabalhos-aprovados.php Acesso em: 10 jun. 2019.

Martins, R. D. M. 2014. Vivências de crianças e adolescentes destituídos do poder familiar em situação de acolhimento institucional. Campo Grande, MS: Universidade Católica Dom Bosco (UCDB). Disponível em: https://site.ucdb.br/public/md-dissertacoes/14426-via-final.pdf. Acesso em: 05 jun. 2019.

Oliveira, S. V. D., \& Próchno, C. C. S. C. 2010. A vinculação afetiva para crianças institucionalizadas à espera de adoção. Psicologia: ciência e profissão, 30(1), 62-84.

Silva, J. A. 2009. Adoção de crianças maiores: percepções e vivências dos adotados. Dissertação (Mestrado). Belo Horizonte, MG: Pontifícia Universidade Católica de Minas Gerais. Disponível em: http://www1.pucminas.br/documentos/dissertacao_jaqueline_araujo.pdf. Acesso em: 01 jun. 2019.

Trindade, V., \& Bartilotti, C. B. (2017). "Não quebrou a corrente, mas abriu um elo entre nós": o impacto da dependência química materna sobre o vínculo mãe-filho. SMAD, Revista Electrónica en Salud Mental, Alcohol y Drogas, 13(1), 4-12.

Vargas, M. M. 1998. Adoção tardia: da família sonhada à família possível. São Paulo, SP: Casa do Psicólogo.

Zappe, J. G., Moura, J. F., Dell'Aglio, D. D., \& Sarriera, J. C. 2013. Expectativas quanto ao futuro de adolescentes em diferentes contextos. Acta Colombiana de Psicología, 16(1), 91-100.

Zem-Mascarenhas, S. H., \& Dupas, G. 2001. Conhecendo a experiência de crianças institucionalizadas. Revista da Escola de Enfermagem da USP, 35(4), 413-419.

\section{Minicurrículo}

Érica Cavalheiro da Silva. Acadêmica do curso de Psicologia da Universidade Regional Integrada do Alto Uruguai e das Missões, Campus Santo Ângelo, Santo Ângelo, Rio Grande do Sul, Brasil

Giana Bernardi Brum Vendruscolo. Mestrado em Saúde e Comportamento. Universidade Católica de Pelotas, UCPEL, Brasil. Especialização em Educação a Distância. Centro Universitário Senac, SENAC/SP, Brasil. 
Como citar: Silva, E.C., \& Vendruscolo, G.B.B. 2021. Vivências de crianças e/ou adolescentes que esperam por adoção tardia. Pubsaúde, 5, a091. DOI: https://dx.doi.org/10.31533/pubsaude5.a091

Recebido: 21 out. 2020.

Revisado e aceito: 28 out. 2020.

Conflito de interesse: os autores declaram, em relação aos produtos e companhias descritos nesse artigo, não ter interesses associativos, comerciais, de propriedade ou financeiros que representem conflito de interesse.

Licenciamento: Este artigo é publicado na modalidade Acesso Aberto sob a licença Creative Commons Atribuição 4.0 (CC-BY 4.0). 